\title{
Will Climate Change Bring an End to the Platinum Age?
}

\author{
Ross Garnaut*
}

The interaction between strong and broadlybased global economic growth and risks of climate change is throwing out the defining challenge of our time. Our response to the challenge will shape the prospects for security and prosperity through the twenty-first century.

I have been bumping into climate change issues for many years. In the early 1990s, my lifelong professional interest in economic development in Asia and the Pacific drew me into conversations with senior policymakers in Beijing about ways in which continued rapid economic growth in China might be reconciled with what was then an emerging international focus on climate change mitigation. My involvement in development in Papua New Guinea drew my attention to the disruption to living standards and established patterns of life among the people of the vast lowlands of the southern side of the island of New Guinea, across the Torres Strait and Arafura Sea, from small increases in sea levels that are already occurring. My work as Chairman of the International Food Policy Research Institute in Washington has made me aware of the high risks of huge disruption to nutrition and more broadly to political stability and economic development in the parts of the world where most of the poor people live. As a resident of southern Australia, and participant in the life of the farming communities on the southwest slopes of New South Wales, I have also shared the growing anxiety about the warming and drying of the climate in recent times.

All of this was, however, at the margins of my professional life until April 2007, when Kevin Rudd, the then Leader of the Federal Opposition, and Anna Bligh, the then Queensland Acting Premier-on behalf of all the Premiers and Chief Ministers of the Australian States and Territories, asked me to conduct a national review of climate change impacts and policies (hereafter the Review). The Review was, in the first instance, commissioned by the Premiers and Chief Ministers. We started work in July 2007 and have been making good progress within that framework. As envisaged by Kevin Rudd in April 2007, the Australian federal election outcome on 24 November 2007 has made the Review a cooperative effort between the Commonwealth and State Governments. The election outcome has brought climate change into the centre of Australian policymaking.

The Review will seek to define a way forward for Australia now in a world that is taking seriously the challenge of climate change. Following on from Sir Nicholas Stern's landmark review released October 2006, the Review will provide an Australian perspective on several issues:

- the impacts of climate change on Australia, directly or indirectly through its effects on other countries;

- the policies that are most suitable for reconciling the maintenance of rising living

* Ross Garnaut is Professor of Economics in RSPAS at the ANU. This paper was presented as the inaugural S.T. Lee Lecture on Asia and the Pacific, the Australia National University, 29 November 2007. For further information on the Garnaut Climate Change Review, please visit <http://www.garnautreview.org.au>. 
standards in Australia and abroad with effective mitigation of and adaptation to the climate change that will inevitably occur;

- how Australia's mitigation efforts can support an effective global approach to mitigation of climate change;

- how we can distribute the burdens of the mitigation and adaptation over time between countries and among citizens in ways that are widely recognised as being fair-for reasons of equity, and also to provide a sound domestic and international political foundation for sustained and effective policy efforts over long periods;

- how we can develop market-based approaches to the mitigation and adaptation wherever these are likely to be effective, and how we can introduce rigour into analysis of the case for other forms of intervention when there is clear evidence of market failure; and

- the appropriate locus of responsibility within the Australian Federation for various aspects of mitigation and adaptation policies.

With the Review Secretariat operating in Melbourne from July 2007, and the Commonwealth component of the Secretariat operating from the Department of Climate Change from January 2008, work is under way on all of these issues. In this paper, I will focus on a few of them: the broad theme of reconciling economic growth with effective mitigation; the links between Australian and international mitigation efforts; and some essential characteristics of market-based mitigation policies.

\section{The inconvenient truth in the Platinum Age}

In terms of speed, magnitude and breadth, global economic growth in recent years has exceeded the average economic growth that was experienced in the two benign post-World War II decades, which came to be known as the 'Golden Age'. The recent experience represents a marked lift in growth rates from those of the last quarter of the twentieth century. Elsewhere I have called the early twenty-first century the 'Platinum Age'.

In historical terms, we are now seeing the extension of the scientific, technological, industrial and commercial revolutions-their origins hailing from Britain and Northern Europe in the late eighteenth century-into the heartlands of the populous countries of Asia. These changes spread through Western Europe and its overseas settlements and to Japan in the nineteenth and early twentieth centuries, and to a number of smaller economies in East Asia in the third quarter of the twentieth century.

The Chinese economy has been growing strongly since the Chinese Communist Party committed itself to international and marketoriented reforms in December 1978. In the early twenty-first century, China has established steady growth at high rates through the maturing of institutions for managing a market economy, deepening integration into the international economy, and upward shifts in savings and investment rates from levels already high by any standard. Sustained high growth during nearly 30 years of reform has made China an economy large enough now for its rate of growth to have a substantial impact on global averages, and also on growth opportunities in other countries.

The global story extends well beyond China. High rates of growth are now well established in India. Vietnam-a country that has more people than any in the European Union-is growing as rapidly and as consistently as India. Southeast Asia as a whole has left behind the sluggish years following the East Asian financial crisis; although it has not returned to the febrile though ultimately unsustainable growth rates of the 1990s before the crisis.

Strong global demand has lifted the terms of trade and accelerated the growth of commodity exporting countries everywhere-from Australia and Papua New Guinea to Russia and the other successor states to the former Soviet Union, Latin America and Africa. The economies of sub-Saharan Africa have been experiencing average growth rates of about 
5 per cent per annum in recent years-for the first time ever over such an extended period.

Evidence is accumulating that the exceptionally high average growth rates of the early twenty-first century are not temporary phenomena. My own assessment about the future of Chinese economic growth is well known; that is, there are reasonable prospects for growth rates in the vicinity of 10 per cent per annum-or even higher for a while-to continue for a considerable period and for growth rates to remain high until average Chinese productivity levels and living standards are approaching the range of industrialised countries in the late 2020s. The new, higher trajectory of Indian growth of about 8 or 9 per cent per annum is soundly based and has strong momentum.

This growth has seen an unprecedently rapid transition of people out of poverty. It is now clearer than ever that the natural course of global development is for more and more of the world's people to aspire to and to realise living standards similar to those in the industrialised economies.

The acceleration of global economic growth would be an unambiguously good thing if it were not for the inconvenient truth that the scaling up of the patterns of life in the industrialised countries to the populous parts of the developing world is unsustainable without major changes in the relationship between economic activity and the environment. The inconvenient truth has, as its most compelling point, the risk of dangerous climate change derived from the dependence of established patterns of modern economic growth on the utilisation of fossil fuels, especially in the energy and transport sectors.

Global fossil-fuel carbon emissions from 2004 to 2006 grew at an annual rate of 3.1 per cent, a rate in excess of that anticipated in many of the international climate change assessments, including the scenarios outlined by the Intergovernmental Panel on Climate Change (IPCC), which were used in the modelling for the Stern Review (IPCC 2000; Stern 2006). While increasing demand in recent years and limitations on the expansion of pro- duction have lifted oil and other energy prices to exceptional levels, impending scarcity is unlikely to provide a substantial constraint on coal and total fossil-fuel consumption in the foreseeable future. It is unlikely that the relationship between fossil-fuel emissions and economic growth will change markedly without effective policy interventions. The recent effects of higher oil prices are instructive. Two highly emission-intensive alternatives-coal and synthetic liquid hydrocarbons (derived from coal, tar sands, shale or natural gas) —are expanding their proportionate global roles. The average amount of carbon per unit of energy used has actually been increasing in the large, rapidly growing developing economies.

It is neither desirable nor feasible to seek the removal of the risk of dangerous climate change through reduction in global ambitions for higher material living standards. The challenge is to remove the link between economic growth and greenhouse gas emissions. Enough work has been done for us to be reasonably confident that there are economically and technologically feasible means of removing this link. The work has also shown, however, that the design and effective implementation of policies that secure the necessary outcomes present immense challenges to national and international polities.

\section{A worse and more urgent problem than we thought: the recent economics and science}

As discussed in a Garnaut Climate Change Review public forum in Melbourne on 14 November 2007, the reality of climate change observed in recent years has surprised mainstream scientific opinion, given the increase in emissions concentrations so far. In addition, the rate of emissions increases has also exceeded that presumed in the most extensively discussed IPCC scenarios. The reason for this is that global economic growth, the energy intensity of growth and the carbon intensity of energy production are all proceeding ahead of expectations. 
My work in 2007 suggested that the IPCC's A1FI emissions scenario 1 - which was thought earlier to be on the extreme high side-could be close to or understate the realities of the early decades of the twenty-first century. In Australia, the CSIRO and Australian Bureau of Meteorology's latest projections under this A1FI scenario show that an increase of $2^{\circ} \mathrm{C}$ by 2070 is virtually certain for most of Australia, and highly likely for the south coast, while there is a 30 per cent chance of exceeding $4^{\circ} \mathrm{C}$ in inland areas.

'Business as usual' is carrying the world towards high risks of dangerous climate change faster than seemed to be the case a short while ago. The need for an effective policy response is more urgent than we thought.

\section{Climate change mitigation as a diabolical policy problem}

As I have worked my way into climate change policy issues over the past six months, the diabolical nature of the policy challenge has become apparent to me, as it did to others before me. Features contributing to its diabolical nature include:

- the uncertainties surrounding relationships between atmospheric greenhouse gas concentrations and the timing and extent of dangerous climate change;

- the long lags between emissions and their impacts, exacerbated by the temporary masking effects of aerosols-making it difficult to rely on observation of impacts to prompt timely policy change;

- the need for unprecedented international cooperation for successful mitigation alongside powerful incentives for individual countries to free ride on others; and

- the complexity of the income distribution effects of climate change and effective mitigation.
The unusual risks and uncertainties in climate change mitigation derive from the science on the relationship between emissions and their consequences, and also from the timing and economic characteristics of emergent technologies. Uncertainty about the science and technology encourages hesitant policy responses, which slows mitigation and raises its costs.

Climate change presents a classic commons problem in that individuals or countries typically gain much more from their use of the resourcethe atmosphere's capacity to absorb emissions without unacceptable risks of dangerous climate change- than they suffer from their own contribution to degradation of the environment. At the national level, all countries except possibly the biggest two emitting countriesChina and the US- have an incentive to free ride on the efforts of others-no matter whether others are taking effective mitigative action.

If there were a single international negotiation to which each country took its own policy position, developed in its own narrow national interest, and in the absence of cooperative communication with others, no countryexcept possibly the big two-would choose to do anything. The result would be the worst possible outcome for most national entities and for the world as a whole. Here we would be dealing with a genuine international 'prisoners' dilemma'. In this sense, the international climate change policy problem is less tractable than multilateral trade negotiations, which embody a perceived but not a real prisoners' dilemma. That is, even though some sectors in some countries would be worse off, all countries as a whole are better off with trade liberalisation-even if it is pursued unilaterally. Despite this more benign reality, negotiations for multilateral trade liberalisation have fallen upon hard times in the twenty-first century. This would seem to augur poorly for a favourable outcome of international negotiation on climate change.

1 In 1996, the IPCC began the development of a new set of emissions scenarios to effectively update and replace the wellknown IS92 scenarios, as described in the IPCC Special Report on Emission Scenarios (SRES). The A1 storyline and scenario family describes a future world of very rapid economic growth, a global population that peaks mid-century and declines thereafter, and the rapid introduction of new and more efficient technologies. A1FI refers to one of the A1 groups-fossil intensive (IPCC 2001). 
Policies that have large effects on income distribution invite fierce contests between competing interests. Climate change policy has three acute equity dimensions:

- An inter-generational equity question. To what extent should one generation be willing to forgo some current consumption to allow greater consumption by future generations? The likely greater prosperity of future generations would seem to argue for slow action. However, we have to come to terms with the possibility of stepwise changes that could fracture central features of economic and political organisation, and radically change features of the natural environment to which human beings currently attach high value.

- An international equity question. The costs of climate change and its mitigation will differ greatly across countries. In general, costs will be greater for developing countries. Attitudes towards international cooperation are complicated by the historical reality that the current high concentrations of greenhouse gases are overwhelmingly the product of past actions by industrialised countries. Moreover, annual additions to atmospheric concentrations per capita from industrialised countries are much higher-by a factor of 13 (for carbon dioxide emissions) between Australia and India.

- A domestic equity question. The price of carbon-the central feature of an effective mitigation regime-will be passed through mainly to households, and disproportionately to those with low incomes. Climate change and its mitigation have the potential to force highly regressive changes in income distribution.

The international equity issues compound the difficulties of the 'prisoners' dilemma' between countries. The inherent incentives for a developing country to do nothing are reinforced by its confidence that industrialised countries should take substantial action first.

There are three possible saving graces in the international space. One is the high level of community support for action in many countries, including Australia. The second is that a start has been made on international cooperation and that some countries have taken steps, though at some cost, towards reduction of emissions. The third is that international climate change policy is not played out just once in a single game; rather, it is played out through interactions over time, allowing countries' policies to influence each other.

On domestic distribution of the mitigation costs, the losers will block effective action politically unless the effects of mitigation policies are recognised widely as being broadly fair. Managers and analysts of the first phase of the European emissions trading scheme (ETS) have recognised that the large and inequitable distribution effects of allocating free permits to established emitters, even when the carbon price was passed on to households, was a fatal flaw.

Questions of distribution are, therefore, fundamentally important not only to distributional equity but to the environmental integrity of mitigation policy.

\section{Resolving the tragedy of the global commons: the only solutions are global solutions}

Australia and the world need a mitigation strategy that can manage uncertainties, is widely considered to be equitable, and breaks through the perverse incentives of the 'prisoner's dilemma'. On environmental grounds, a global mitigation budget needs to be expressed in terms of a goal of stabilisation of greenhouse gas concentrations at a specified parts per million (ppm) of carbon dioxide equivalent $\left(\mathrm{CO}_{2}\right.$-e). This would generate an amount of greenhouse gas emissions-a certain number of gigatonnes of $\mathrm{CO}_{2}-\mathrm{e}$-that could be emitted up to a stabilisation date, if the risks of dangerous climate change were to be held within acceptable limits. International discussion on an appropriate global budget needs to be informed by scientific estimates of the impacts of different emissions concentrations, and needs to be based on assessment of the mitigation costs and the relative weight placed on welfare of current and future generations. 
Currently, the concentration of $\mathrm{CO}_{2}$-e in the atmosphere is about $455 \mathrm{ppm} \mathrm{CO}_{2}$-e. There is a widespread view-based on the climate science-that the risks of dangerous climate change and the risks of abrupt climate change are already at unacceptably high levels. Another view argues for an objective of stabilisation at 550ppm $\mathrm{CO}_{2}-\mathrm{e}$, on the grounds that any global target below this level would be impractical-a view to which Stern (2006) was inclined.

The movement towards an effective mitigation strategy must begin with a broad international understanding that a global emissions budget is necessary. The global budget represents the total volume of emissions that can be absorbed into the atmosphere over a specified period without unacceptably high risk of dangerous climate change. This should provide a framework for the second step-an appropriate level of ambition for mitigation. The third and most difficult step is to allocate the remaining global capacity to emit greenhouse gases among countries.

It is unlikely that a sound agreement on a global emissions budget will emerge from a negotiation in a single, large, multilateral, intergovernmental meeting. The incentives facing individual delegations in such a negotiation are all wrong. Each representative is under pressure to secure a better deal than others.

The prospects of agreement are better from a 'messier' process in which countries and groups of countries address in many fora the ambition and allocation of a global budget. Principles are articulated by some players and are embodied in policy by others. Successive multilateral negotiations allow countries to learn what others are prepared to do. The game theory problem then becomes that of a repetitive game with signalling and learning.

This is no small mercy. Formal game theory analysis of prisoners' dilemmas has shown that with sufficiently sophisticated-but not overly complex-strategies, it is possible for cooperative, rather than mutually harmful, behaviour to emerge as a stable equilibrium (Axelrod 1984). Successful strategies require some countries to deliver mutual benefits ahead of others; to reward cooperative responses from others by going further; to punish uncooperative behaviour; and to be clear about their strategies.

In the circumstances of climate change policy, it is impossible to avoid the imperative that industrialised countries would take effective action first. This notion has been widely recognised as being fair and, given realities of historical responsibility and existing capacity to support the necessary investment, it is the only basis from which early steps towards mitigation could be taken. The decision not to ratify the Kyoto Protocol by the US and Australia after the election of the Bush administration seven years ago was of historic importance in disrupting an international approach. Australia's return to the international fold, following the election of the Rudd Labor Government, is an important corrective measure.

It is an equally important reality that there will be no adequate global mitigation unless the major developing countries-first of all China, India and Indonesia-soon become part of the global mitigation effort. The inclusion of these countries, after earlier actions taken by industrialised countries, is an urgent matter. With industrialised countries starting to act, participation in trade in emissions permits and share in the benefits of the industrialised countries' research and development can provide important incentives for developing countries to follow. These add to the central incentive: the shared interest in a successful outcome.

Responses to transgressions or noncooperation must, however, be considered and measured carefully. It is unnecessary and undesirable for 'punishment' in response to others' non-cooperation to be based on retreat by cooperating countries from mitigation policies; it would be far better for punishment to be applied outside the sphere of climate change mitigation. There is already influential talk in the US-among those who support firm mitigation policies at home-and the European Union of trade sanctions against non-cooperating countries. This is likely to become part of the framework for enforcement of cooperative behaviour on mitigation. I am 
concerned about the risk of capture by other interests favouring protection for other reasons. Withdrawal of opportunities for trade in greenhouse gas credits and development assistance would seem to be less problematic instruments for punishment.

What principles might guide the allocation of a global emissions budget across countries? To be widely accepted as being reasonable, the principles will need to be simple, transparent and readily applicable. In the end, they will need to give much weight to equal per capita rights of emissions. They will need to allow long periods of adjustment towards such positions-with the over-riding requirement to stay within an environmentally responsible global emissions budget. One possible way of bringing these two elements together would be the contraction and convergence approach that has been discussed favourably in Germany and India at times in the past.

The world will need to provide headroom for emissions growth in rapidly growing developing countries, within a general principle of sharing the adjustment burden. The headroom could take the form of challenging emissions intensity targets-for example, with emissions intensity of output falling by more than half of the GDP growth rate-for developing countries growing too rapidly to hold to a budget tied mechanically to contraction and convergence. The principles will need to embody industrialised-country commitments to investment in research and development (R\&D) and the subsequent diffusion of technologies to developing countries.

A limit, however, would need to be placed on the provision of headroom for rapidly growing developing countries. For example, if the contraction and convergence approach were to be accepted as the first organising idea, and an emissions intensity alternative introduced for rapidly growing developing countries, the headroom could be withdrawn at the point where the developing country's rising emissions per capita reach a benchmark trajectory in per capita emissions. This benchmark trajectory could be based on an average of the emissions profiles of moderately emitting industrialised countries-such as, Europe,
Japan and New Zealand, which would be expected to be much lower than at the present point where the two trajectories intersect.

The proposals for equitable allocation of a limited global emissions budget are at an early stage of development. While being one of the three exceptionally large per capita industrialised-country emitters, despite the US and Canada, Australia's proximity to the rapidly developing countries of Asia gives us important perspectives to bring to the international discussion of these matters.

The keys to the eventual emergence of an acceptable basis for allocating a global emissions budget would be the widespread acceptance that it is essential to reach an agreement; that the allocation formula is simple; and that it is impossible to cover every valid special case. The costs of living within global and national budgets would be lower if the allocation of rights to emissions were tradable between countries, under principles that are adumbrated below.

\section{Australia's interests}

What should Australia aim for while the world discusses a global emissions target?

Australia is likely to be damaged more than any other industrialised country by climate change:

- Our environment is already dry and highly variable. This will be exacerbated with climate change, with the effect on agriculture and water supplies being particularly pronounced. The climate models tell us that the reduction in precipitation within global climate change may be pronounced in the latitudes of southern Australia, where most Australians live.

- Our location means we are surrounded and affected by developing countries that would be affected disproportionately by dangerous climate change.

- Our terms of trade are affected more favourably than those of any other industrialised country by the maintenance of the strong Asian and global economic growth of the Platinum Age. 
At the same time, Australia is well placed to do well as part of an effective global climate change mitigation effort.

- We have exceptionally rich resources for solar, geothermal and wind energy and possibly for biofuels from the savannahs that currently make minor contributions to food production.

- Our large livestock industries are less emissions-intensive than our competitors in Europe, Northeast Asia and North America.

- We have large resources of high-qualitythat is, low emissions per unit of energycoal, which means that our share of the global coal supply would rise under an effective global mitigation regime.

- We have large deposits of natural gas and uranium, the exports of which would increase in a world of major and effective climate change mitigation.

- We have an exceptional endowment of favourable sites for carbon capture and storage- the best of the known resources being favourably located in relation to the coal-using industrial centres of southeastern Australia.

- Lastly, we have an exceptional human resource base in engineering, management and finance related to the resources sector, which places us well for competitive participation in innovation in the emerging, low-emissions energy industries.

All of these Australian strengths facilitateand render less costly-domestic climate change mitigation. Within an appropriate policy environment, these strengths will provide a basis for new export opportunities, especially in the context of effective global action on climate change mitigation.

To date, Australians have been encouraged to concentrate on an unhappy part of the reality: that mitigation is a risk for Australia due to the disproportionate importance of our trade-exposed, exceptionally emissionsintensive industries.

Without an adequate international framework to deal with these industries, domestic action could lead to movement of these industries overseas, reducing to some extent the value of Australia's economic output and, in the worst-case scenario, perversely affecting global emissions. The political economy of rent-seeking behaviour converts this possibility into a compelling argument in every country, whether or not it has substance in particular cases. There is, consequently, a tendency for systematic exclusion of the most emissions-intensive industries from mitigation disciplines, raising the mitigation cost for the economy as a whole.

The second-best solution, after the application of similar emissions pricing in all relevant countries, is to ensure that the exceptionally emissions-intensive, trade-exposed industries-non-ferrous metals smelting, steel, cement and a small number of others-are subject to similar disciplines in major producing economies for each commodity; comparable in effect to the application of the general mitigation regimes adopted by major economies. Objective analysis of the policy regimes applied to the emissions-intensive industries in other major economies, including China, suggests that the world is much closer to this point now than is acknowledged in the Australian discussion of climate change mitigation policy. Pending the establishment of efficient international regimes, it will be sensible to provide appropriately calibrated assistance to Australia's trade-exposed, emissions-intensive industries.

Taking everything into account, it is strongly in Australia's interest to encourage effective global approaches to mitigation around ambitious global targets. Australia can move towards securing its interests in a number of ways. First, ratification of the Kyoto Protocol will strengthen Australia's voice in global discussion. Second, leadership could be shown by supporting the emergence of understandings, at the Bali Climate Change Conference and beyond, on incentives for reducing emissions from deforestation; on the need for an ambitious global budget; and for principles for allocation of the global budget among countries. Third, Australia can ensure that its own mitigation regime fits productively into the international regime that we judge to be feasible for the future. Our announced emissions targets should relate appropriately to the 
emissions budget, which we judge to be likely to emerge from a global discussion of principles for allocating rights among countries. A complementary step would be to work with others, including developing countries in our region, to encourage their development of internationally compatible mitigation policies, encouraged by opportunities for trade in permits and for technological exchange.

Australia, alone or with others, could act usefully on the basis of principles that it judges to have prospects as part of an eventual global understanding on allocation of emissions rights. We are too late to be one of the first to move among industrialised countries, but we can cease to be a laggard. Australia's adoption of an efficient mitigation approachdesigned carefully to encourage others to move towards effective contributions to global climate change mitigation-can play an important international role. Our action would be a step towards resolution of the repeated 'prisoners' dilemma'.

Finally, Australia has a vital interest in the acceleration of the development of new cleanenergy technologies. It has an especially strong interest in carbon capture and storage from coal. It shares this interest with other economies with large or politically sensitive coal endowments, including those in the European Union and China, a shared interest which provides a strong basis for international cooperation. Australia can usefully take a lead in promoting this cooperation.

\section{Living within Australia's emissions budget}

At the centre of a climate change mitigation strategy is the setting of a price for emissions, paid by anyone who emits greenhouse gases. The price should reflect the environmental costs of the emissions that would not be paid by people whose decisions generate them. Once the price is in place, the private decisions made by individuals and firms in their own interests can be expected to establish the socially appropriate balance between environmental and other interests. It will lead to market decisions that keep Australia's emissions within its national budget.

Establishing the right price is a complex matter. A public lecture that is part of the Review will address the issues in details in early 2008. Here I will raise only some of the issues.

If the price is established at the right level, there is no need for other policy measures to tip the balance of private decisions on supply and use of fossil-fuels towards low-emissions technologies. During the transition to an environmentally and economically rational emissions price, a case can be made for other measures, such as a mandatory renewable energy target, as long as the price-now and expected in future-is insufficiently high to ensure that Australia lives within the national emissions budget.

There are two ways of setting an emissions price. (Because we are talking mainly about carbon dioxide emissions, I will use the term 'carbon price'). One is through a carbon tax. The other is to set a limit on current and future carbon emissions to require a permit to emit carbon dioxide, to allocate permits up to that limit, and to let the market set the carbon price (an ETS).

An ETS and a carbon tax are market-based approaches to confining emissions within a specified budget. The essential differences between a well-designed and credible ETS and a well-designed and credible carbon tax are not as large as often supposed. Many economists prefer a carbon tax because they hold the view that the alternative is not a well-designed and credible ETS, but a distorted one surrounded by uncertainty about key parameters. It could be said that they have experience to date from the established carbon ETSs on their side.

Those who prefer an ETS compare its ideal qualities with a carbon tax. The international community of industrialised countries, including Australia, have opted for an ETS. I am comfortable with the Australian decision, as long as we are clear in our minds about the conditions that are necessary for an ETS to achieve its environmental objective at an optimally low economic cost. There are two 
important advantages of an efficient ETS. First, allowed to do its job without political limits or adjustment, an ETS can be relied upon to constrain emissions within the specified total budget. Second, it sets the current and future prices directly, without bureaucratic clairvoyance about the many relevant and continuously changing influences on the supply and demand side for emissions permits. The task is to establish in Australia a well-designed and credible ETS.

It should be noted at the outset that for some countries-and probably for all developing countries for the time being-an efficient ETS is probably impractical, and a marketbased mitigation effort would need to be built around a carbon tax. Ways can be found to secure mutual gains from international trade in emissions rights between ETS and carbon tax regimes.

In Australia, an efficient ETS should be built first of all upon a firm and credible greenhouse gas emissions budget, covering the many future years that will be affected by current decisions. The size of the budget would relate appropriately to the global budget established and enforced as Australia would like to see, and relate to the principles for allocation of that budget that Australia judges to be a reasonable and feasible basis for ultimate international agreement.

The game theory considerations discussed earlier argue for multiple carbon budgets: one representing what Australia is prepared to do initially as part of the industrialised-country contribution to start the game on a favourable basis; and the others representing what Australia would be prepared to do in the context of an effective, global agreement. There is negligible risk that an emissions-reduction schedule culminating in a 60 per cent reduction from current (or Kyoto 2008-12) levels by 2050 will be more restrictive than would be required as Australia's contribution to enforcement of an environmentally satisfactory global budget. Such an emissions-reduction schedule could turn out to be a reasonable first step, within the context of what other industrialised countries-including the US after 2008-are prepared to do.
The likelihood of a tightening of the Australian emissions budget after the establishment of the ETS is a challenge for the credibility of the system. The possibility of change, its extent, and the circumstances under which it would occur would need to be defined as tightly as possible at the time the ETS is established.

The binding budget, or budgets, should be specified as the total amount of emissions over a long period. Short and medium-term targets, such as the 2050 goal of reduction by 60 per cent of the 2000 emissions, can be announced usefully as a guide to market price formation, and to the timing of the release of permits. But an efficient ETS will allow flexibility in the timing of the use of permits within a firm total budget.

The problem of allocating a fixed, multidecade budget of greenhouse gas emissions over time at the lowest possible cost is familiar from resource economics as one of optimal depletion of a finite resource. A free and credible market would establish, in units of the resource, a spot price and a forward price curve that rises at the relevant interest rate. The spot price would not be low from the perspective of current Australian discussion, and the long-term price would be high. Together, the spot price and forward prices would be high enough to cause Australia to live within the total emissions budget.

The spot and forward prices would adjust together in response to new information. For example, new information suggesting improved prospects for low-cost carbon capture and storage a decade from now would lower the whole price curve, spot and forward, with the price still rising at the interest rate from the new, lower level. The lower price would reduce pressure for abatement from other sources, now that there would be greater confidence in future abatement through carbon capture and storage. On the other hand, a disappointment of expectations about the future prospects for low-cost carbon capture and storage would raise the whole price curve, still with the future prices rising at the interest rate from the new, higher spot price. The higher price would increase pressure for abatement from other sources. 
The market for gold illustrates how a perfectly competitive, deep and mature market for an exhaustible resource results in a forward price curve, with price rising at the interest rate. This price curve provides fundamental stability to the market and opportunities for hedging price risks and adjusting quickly to new information.

The central challenge is to establish credibility. The ETS will work as the main instrument for achieving abatement targets only if the greenhouse gas budget and the ETS structure are credible-if the market accepts that they will not change over time in response to adjustment difficulties and political pressures. Much thought needs to be given to expedients that contribute to credibility: legislative entrenchment of the budget and the system; securing the property rights of emissions rights holders; and administration of the system by a well-resourced independent authority.

An efficient ETS would separate the distribution of the value created by making emissions permits scarce and the allocation of permits. The economically efficient as well as transparent way of allocating permits is to sell them through a competitive process. On the basis that this major environmental reform is not meant to increase arbitrarily the proportion of the economy under the control of the public sector, the proceeds of the sale of permits should not be available for general government purposes, but should be identified separately for return to the community.

On the basis that this major environmental reform is not meant to have large and arbitrary effects on income distribution and, in particular, not to redistribute income away from people on low incomes, that part of the carbon value secured by sale of permits that is passed on to households could be returned to households in an equitable and economically efficient way. Any part of the carbon value associated with demonstrated compression of profit margins in the business sector in the early years of the ETS could be returned in an economically efficient way to relevant parts of the business sector. As already noted, there are good reasons for special treatment of exceptionally emissions-intensive, trade-exposed industries during the transition to widespread and broadly comparable international carbon pricing. The carbon price that emerges from an efficient market would force enough structural change to achieve the emissions budget.

Finally, it is worth discussing the difference between the price of carbon and its cost to the economy. The cost to the economy is not, as some have suggested, the carbon price set for emission permits. It has been a fallacy of the Australian discussion to date to equate the carbon price to economic cost.

In the same way as the Australian economy did not contract in response to the introduction of the GST, nor will the economy contract with the introduction of an ETS in Australia. To understand the reason for this, we need to trace the impacts of a carbon price as it flows through the economy. There is no cost to the overall national economy from that part of the carbon price absorbed by business or passed on to households. The only cost to the economy is the expenditure on substitutes, net of existing higher costs imposed through mandatory schemes.

The Stern Review estimates that the cost of stabilisation of greenhouse concentrations at an acceptable level would total around one per cent of the world GDP. Cost estimates for Australia are in a similar range. These costs do not mean a reduction from current income levels, just smaller increases in future incomes. An impact of 3 per cent on GDP in 2050 would mean that Australia's GDP would treble by 2051 rather than 2050.

If the price of emission permits, therefore, is not all a cost to the economy, where does this price impact go? The part not used to pay the costs of more expensive alternatives in supply or demand goes to whoever receives the value embodied in the permits. Most of the price impact, especially in the early period, is likely to be passed through to households. The value is not lost; it is simply transferred, in this case, from households to whoever receives the value from the permits. If the scarcity value of the permits were collected by government and passed back to households in appropriate ways, there would be no negative income effect on households. 
Similarly, that part of the price of permits that does not pay for the higher costs of substitutes, and is not passed on to households, may compress profit margins in energy-intensive businesses, whose energy is derived from emission-intensive sources,. Again, if the scarcity value of the permits were collected by government and passed back to exceptionally impacted businesses in appropriate ways, there would be no exceptionally large effect on the profits of energy-intensive industries.

The overall redistribution of income could be large by any standards-including redistribution away from low-income households. Without appropriate policy responses, the redistribution of income will lead to political resistance to economically and environmentally efficient carbon prices. For these reasons, efficient distribution of the value of the permits is essential to the efficiency of an ETS, as well as to equitable distribution of its impacts.

\section{Conditions under which international trade in emissions rights will help to reduce the costs of Australian and global climate change mitigation}

International trade in emission permits can reduce the cost to Australia and other countries of living within a specified carbon budget. Careful thought must be given to the conditions under which genuine gains from trade will be achieved. The conditions would include:

- all countries having a similar definition of a carbon unit;

- all countries having monitoring and enforcement mechanisms to a minimum standard;

- each country having a defined budget for the period during which the trade is to occur and for which the permits will be valid, with only the 'savings' from the defined budget being available for trade; and

- countries not having individual price caps or floors-otherwise one country could flood the market with additional permits, or be forced to buy up permits without limit. Some countries may opt for an ETS while others might adopt a tax or direct regulation.
The alternative paths are more likely to be chosen by developing countries in which the application and administration of a tax is more feasible than that of an ETS. In such cases, international trading of emissions allowances would still be possible, perhaps through a national authority, as long as the basic conditions about defining units of emissions are met.

Considering the question of when different national schemes should be linked is more difficult. Any established system will attract vested interests around the status quo, making it better to establish a multi-country system from the beginning than to cause surprise while the ETS is operating. In the absence of prior agreement, there would be value in announcing at the beginning of the ETS the conditions on which international trade in permits would be introduced. The announcement should include details of the timing of expansion of opportunities for trade and the conditions that would need to be met before the scope for trade would be expanded.

\section{The role of government beyond the} ETS

The over-exploitation of the atmosphere as a global commons is the primary climate-change market failure. There are, however, several other sources of market failure that need to be corrected if private decisions within a market context are to lead to minimum-cost realisation of abatement objectives. These fall into three broad areas: research and development, infrastructure provision, and information.

The presence of large external benefits from private expenditure on $\mathrm{R} \& \mathrm{D}$, and more generally on innovation, means that putting a price on carbon alone will not lead to economically optimal levels of activity. The case for government support for R\&D is well established. The challenge for policymakers is to set up institutional arrangements that allocate scarce public resources efficiently among areas of potential investment in R\&D. The Review will articulate relevant principles.

There are also market failures in the transaction space-that is, the market alone might 
fail to create the opportunities for transactions to take place. There could be a need for a government role in the establishment of efficient networks for electricity transmission, gas transportation, and the agglomeration of carbon dioxide for sequestration.

The third group of market failures arise from information failures. The implications of climate change are so complex and pervasive that consumers can hardly be expected to gather complete information.

There are also market failures on the adaptation side of the climate change challenge. While I have not spoken much of this here, adaptation policy is essential. We will face an uncomfortable degree of climate change regardless of the success of mitigation efforts. How governments and communities plan for adaptation will influence strongly the social and economic costs of climate change.

\section{Will climate change and humanity's response to it end the Platinum Age?}

There are several ways in which climate change could end the Platinum Age. Climate change itself could disrupt seriously economic life and political stability in some major economies, to an extent that undermines the foundations of sustained, rapid, internationally oriented growth.

In the scenarios defined by the IPCC that have drawn most attention, the main impacts of inadequately mitigated climate change could come after China's transition to an industrialised economy neared completion. There are, however, large statistical variations above and below the central expectations, and the business-as-usual rate of growth in emissions is-and is likely to be-far more rapid than assumed in the standard projections. The odds are higher that climate change itself would disrupt the extension of high living standards to other parts of the developing world after the substantial completion of the Chinese transition.

Major shocks can affect economic activity beyond the immediate and direct economic impacts. The effects of the 1890s depression in eastern Australia, and of the global Depression of the early 1930s, were magnified many times by the changes in attitudes to economic institutions and policies that emerged from them. The financial crisis in Indonesia in 1997 and early 1998 was converted into a catastrophic decline in output and incomes by its interaction with a fragile political system. These are among the effects anticipated from unexpectedly large climate change impacts. It is worth keeping in mind that carefully designed adaptation policies can reduce the chances and impacts of major shocks.

The Platinum Age could be disrupted also by poorly thought out approaches to climate change mitigation. Stern (2006) has presented the results of work that suggests that the global costs of effective mitigation need not be large. On the basis of the application of this analysis to the central, forward-looking scenarios of the IPCC, the continuing costs of holding global emissions to levels that reduce greatly the risks of dangerous climate change would be about one per cent of GDP, or a modest fraction of one year's increase in global output. The costs would be somewhat greater if, as I think likely, the underlying rates of emissions growth in the Platinum Age are much greater than presumed in the IPCC scenarios and the Stern Report.

The costs of climate change mitigation in practice would, however, depend on the nature of the policies applied to it, and the manner of their implementation. Costs would be minimised within steady policies that, over long periods, provided incentives that placed with private parties the full external costs and benefits of decisions taken by people and businesses everywhere. Such approaches would allow private decisions to shape the processes of change efficiently within market contexts.

Poor design, or tardiness in implementation, would increase the costs of mitigation immensely, and compromise the mitigation effort. Progress that is judged later to be inadequate is likely to be associated with policy panic, instability and belated concentration of adjustment into disruptively short periods. There is also the ever-present danger of mitigation policies-with their potential to have large effects on the distribution of incomes- 
being encrusted with the usual political economy of rent-seeking behaviour by vested interests, and becoming intertwined with the familiar distortions in public policies related to trade and investment. For individual countries, and for the world as a whole, such policy distortions can make the difference between strong economic growth and stagnation.

Income distribution effects will need to be taken into account in policy design. It is important that there is analytical rigour in design and discipline in implementation of policies intended to secure equitable distribution of the effects of mitigation. Inefficient distribution-an indiscriminate spraying of compensation towards interests that press strongly for it-would increase greatly the ultimate costs of mitigation.

Climate change and poorly designed responses to it could bring the Platinum Age to an end. But if they do, it will represent failures in the design and execution of policies. Australia can play a significant role in the international community avoiding failure.

\section{References}

Axelrod, R., 1984. The Evolution of Cooperation, Basic Books, New York.

Intergovernmental Panel on Climate Change, 2001. The Scientific Basis, Cambridge University Press, Cambridge. Available online at <http:// www.grida.no/climate/ipcc_tar/wg1/index.htm>, accessed on 30 January 2008.
Nakicenovic, N. and Swart, R. (eds), 2000. Special Report on Emissions Scenarios, International Panel on Climate Change of World Meteorological Organisation and United Nations Environment Programme.

Stern, N., 2006. The Economics of Climate Change: the Stern review, Cambridge University Press, Cambridge. 